"We believe that the potential waves are due to the spontaneous beat of an area in the occipital cortex which is normally occupied by activities connected with pattern vision. When the area is unoccupied the neurones discharge spontaneously at a fixed rate (as in other parts of the central nervous system) and tend to beat in unison. Visual activity and widespread non-visual activity break up the synchronous beat by exposing the area to nonuniform excitation. In man, a large area is normally occupied with visual activites; thus when the area has nothing to do and is free to develop a synchronous beat the potential changes are large enough to be detected outside the skull. It appears that the area does not remain permanently unoccupied if vision is lost : in subjects who are blind it must have become more accessible to the rest of the brain.

"The close relation of the area to the visual mechanism is confirmed by the fact that the frequency of the rhythm can be altered by exposing the eyes to a uniform field which flickers at varying rates. The waves then tend to occur with the same frequency as the flicker. The frequency of the spontaneous rhythm varies within narrow limits in different subjects, but there is much individual variation in the persistence of the rhythm, uniformity of $\vec{c}$ the waves, etc."

\title{
THE REGULATION OF SQUINT TRAINING
}

I have been requested by the members of the Orthoptic Council to write a short description of its aims and objects, and I have endeavoured in the following remarks to put forward their views. As it will be seen below, the Council is up to the time of writing, representative of three hospitals, the ideas embodied in the following article being the result of their combined deliberation.

J. D. Magor Cardell.

Orthoptic training is in its infancy, but already holds an established place in the treatment of squint. To prevent this comparatively new form of treatment from being wrongly exploited N it is very necessary that it should be regularized and its exponents supervised. The trainees should, in the first place, have a certain standard of education and should receive instruction of an approved $\omega$ standard, uniform throughout the country. They should in their practice obey ethical rules which will place them in a definite $\underset{\Phi}{\stackrel{0}{\Phi}}$ relationship to medical practitioners, protect them and those who 용 
employ them, from quackery, and give them a proper sense of responsibility and pride in their profession. They should, above all, be restrained from accepting employment by interests outside the medical profession. Only on these conditions will a body of orthoptic trainers grow which will have the aims and incentives necessary to conscientious and reliable work. The necessity of this has been realised by several hospitals which have squint training centres.

The Central London Ophthalmic Hospital and the Royal Westminster Ophthalmic Hospital, each elected two representatives from their staff to form an Orthoptic Council. Their number has recently been augmented by a surgeon from the Children's Hospital, Birmingham, and a member of the staff of the Birmingham Eye Hospital, and St. Mary's Hospital, Paddington, has asked to be included in the scheme. The members of this Council are re-elected every year and have been entrusted with the task of evolving a set of ethical rules, a syllabus, arrangements for periodical examinations, the granting of certificates of proficiency and the keeping of a temporary register of certified orthoptic trainers. This register will later be in the hands of the Council of British Ophthalmologists and will be kept up to date, and published in such a way that hospitals or surgeons requiring the assistance of a squint trainer may be certain of obtaining one who is properly trained. The ethical rules are directed to the encouragement of proper professional conduct both in relation to members of the medical profession and amongst the trainers themselves. Students must promise to abide by these rules before training is commenced, and infringement of them would, at the discretion of the Orthoptic Council, lead to cancellation of the certificate of proficiency and removal from the register.

The fixing of a syllabus is necessary to the maintenance of a proper standard of instruction and examination.

Examinations are held every six months, and bear a relation to the academic year, permitting of a full course of instruction before the candidates present themselves to the Examiners. They are conducted at a time and place deemed suitable by the Orthoptic Council. They may thus be held outside London for the benefit of provincial students. The examiners are appointed by the Council, and include ophthalmic surgeons, ophthalmologists taking an active part in the practical working of orthoptic clinics, and squint trainers.

The written questions and oral examinations are so chosen and marked that practice has a preponderance over theory. A high standard must be attained before the candidate can satisfy the examiners. The examination will be open to the scrutiny of the Council of British Ophthalmologists. 
Mention of some of the regulations may prove of interest. A candidate before commencing training must be 17 years of age, and have passed the school certificate, or an equivalent examination.

Students wishing to be trained will be required to agree to a list of regulations controlling the principles and practice of orthoptics which contain, inter alia, statements that:

1. They shall only work with, and under the direction of, fully qualified medical practitioners engaged in ophthalmology.

2. They shall not prescribe glasses or medicaments.

3. They shall not advertise.

4. They shall abide by the decision of the Orthoptic Council.

5. They shall employ no secret treatment.

6. They shall not train students who will not enter under the engagements required of all squints trainees by the Council.

As regards examinations - to quote two of the rules :

A candidate must be 18 years of age, and a proper period of $\overrightarrow{7}$ training must have been undergone at a centre recognized by the Council.

An attempt has been made to limit the number of students in order that, after paying fees and spending valuable time on $\vec{\varphi}$ training, qualified trainers will have a reasonable prospect of employment.

By these means the Council has endeavoured to regularize the profession of squint training and to give it a status worthy of its aims and objects.

\section{ABSTRACTS}

\section{I.-MEDICAL OPHTHALMOLOGY}

(1) Rohrschneider, W. (Berlin). - The frequency and type of eye lesions in active tuberculosis in other organs. (Häufigkeit und Formen des Augenerkrankungen bei aktiver Tuberkulose anderer Organe). Zeitschr. f. Augenheilk., Vol. LXXXI, p. $197,1933$.

(1) Rohrschneider reviews the statistical literature on the incidence of eye lesions in pulmonary tuberculosis and finds only 38 eye cases in 42,191 general cases-an incidence of about 1 in 1,000 . If, however, cases of tuberculosis spread by the blood stream are considered (bone, joint and genito-urinary system), the incidence is much higher-17 in 181 (consisting of four cases of $\stackrel{\mathscr{Q}}{?}$ 